\title{
Numerical simulation of scaling-up for AEC-MBRs regarding membrane module configurations and cyclic aeration modes
}

\author{
Min Yang ${ }^{\mathrm{a}, \mathrm{b}, \mathrm{c}}$, Mengmeng Liu ${ }^{\mathrm{a}, \mathrm{b}, \mathrm{c}}$, Dawei $\mathrm{Yu}^{\mathrm{a}, \mathrm{b}, \mathrm{c}}$, Jiaxi Zheng ${ }^{\mathrm{a}, \mathrm{b}, \mathrm{c}}$, Zhichao Wu ${ }^{\mathrm{d}}$,
} Shuguang Zhao ${ }^{\mathrm{a}, \mathrm{b}, \mathrm{c}}$, Jiang Chang ${ }^{\mathrm{e}}$, Yuansong Wei ${ }^{\mathrm{a}, \mathrm{b}, \mathrm{c}, *}$

a Department of Water Pollution Control, Research Center for Eco-Environmental Sciences, Chinese Academy of Sciences, 100085 Beijing, China

b State Key Joint Laboratory of Environmental Simulation and Pollution Control, Research Center for Eco-Environmental Sciences, Chinese Academy of Sciences, 100085 Beijing, China

c College of Resources and Environment, University of Chinese Academy of Sciences, 100049 Beijing, China

d College of Environmental Science and Engineering, Tongii University, 200092 Shanghai, China

e Beijing Drainage Group Co., LTD, 100044 Beijing, China

\section{G R A P H I C A L A B S T R A C T}

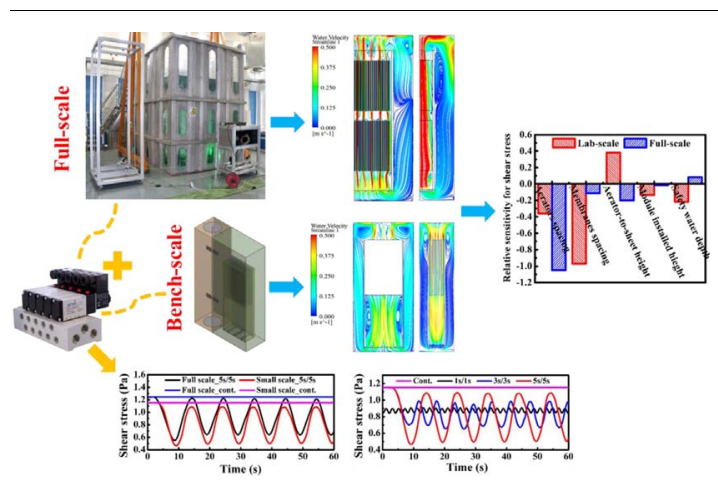

\section{A R T I C L E I N F O}

\section{Keywords:}

Membrane bioreactor

Scale-up

Simulation

Computational fluid dynamics

Cyclic aeration

\begin{abstract}
A B S T R A C T
The airlift external circulation membrane bioreactors (AEC-MBRs) have been attracting attentions due to their capabilities of nutrient removal with lower energy demand and smaller footprint. The gap between laboratory study and full-scale AEC-MBRs regarding hydrodynamics needs to be addressed. In this study, impacts of seven design variables and cyclic aeration modes on hydrodynamics were studied for the scale-up of AEC-MBRs with computational fluid dynamics modelling. The results demonstrated that shear stress on membranes was $14.7 \%$ higher in full-scale MBR with only $15 \%$ of $\mathrm{SAD}_{\mathrm{m}}$ of lab-scale MBR while it showed an overall higher sensitivity to the design variables in lab-scale MBRs. Cyclic aeration modes created a sinusoidal pattern of shear stress and generated more fluctuations and were expected to reduce more irreversible fouling. When a shifting frequency of $5 \mathrm{~s} / 5 \mathrm{~s}$ was applied in AEC-MBR, $50 \%$ of aeration energy was reduced and yield water with good quality was harvested.
\end{abstract}

\footnotetext{
* Corresponding author at: Department of Water Pollution Control, Research Center for Eco-Environmental Sciences, Chinese Academy of Sciences, 100085 Beijing, China.

E-mail addresses: yangmin1113@126.com (M. Yang), yswei@rcees.ac.cn (Y. Wei).
} 


\section{Introduction}

Known as an advanced wastewater treatment technology, membrane bioreactor (MBR) has many advantages such as smaller footprint and solid free effluent among others, but it still encounters the difficulties to mitigate membrane fouling in a cost-effective way (Chen et al., 2016; Judd, 2011; Wang et al., 2014 b). Hydrodynamic condition, apart from thermodynamics (Cai et al., 2017; Zhang et al., 2017), is related to configuration design and system operation and is thus one of the main considerations to tackle such difficulties. For decades, numerous papers and books focused on MBR hydrodynamics have promoted the better understanding and thus the development of this field. The two phases (gas-liquid) cross-flow is now commonly employed because high liquid velocities will occur in the falling film which forms between bubbles and the surface of membrane and the eddies that are generated in the wake of a rising bubble of air (Berube and Lei, 2006; Cui et al., 2003). Actually, the membrane module configurations do matter to obtain a high and even membrane scouring in the two-phase flow. Ndinisa (Ndinisa et al., 2006) characterized the two-phase flow in submerged flat sheet membrane modules aiming at fouling control through computational fluid dynamics (CFD) simulation. They found that the presence of baffles completely stopped the meandering of the gas and liquid stream resulting in the bubbles rising in a straight path and the area of the membrane scoured by the air bubbles increases. Liu (Liu et al., 2016) simulated the impact of eight design variables, including fiber orientation, filtration tank geometry and aeration design, on the hydrodynamics and aeration patterns in a pilot scale membrane bioreactor. Their results revealed that shear in the upper section of the membrane module increased by $30 \%$ with the inclusion of baffles. The shear stress get more homogeneous and larger by rotating nozzle aperture to face to the bottom of the tank, locating the air diffusers $100 \mathrm{~mm}$ below the bottom of the module and aligning the aeration pipe in parallel with the direction of the fiber bundle. However, the results from bench or pilot scale experiments are not always correlated to the application in full-scale plants due to the Reynolds number affected multi-phase flow of liquid, suspended solids and dispersed air bubbles which physically interacts with the membranes (Buetehorn et al., 2012; Yang et al., 2006). Actually, while many publications on hydrodynamics are being conducted regarding configuration optimization, significant research efforts are needed to address the scale-up issues. Aeration system has a most influential impact on membrane fouling reduction in MBR. In specific, aeration will drive the bulk liquid to form an air-liquid-flocs flow in MBRs. The shear stress, generated on membrane surface on which the bulk fluid flow scours, will mitigate the foulants adhered and will back-transport the foulants from adhesion with its induced diffusion force (Chen et al., 2017; Zhao et al., 2016). Many numerical papers worked on this area including the bubble shape and size, nozzle direction, installed position of aeration tubes, aeration intensity, etc. (Khalili-Garakani et al., 2011; Liu et al., 2016; Wang et al., 2014a). Unfortunately, very limited publications evaluated the hydrodynamics to the aeration patterns, e.g., intermittent or cyclic aeration, which were experimentally proved to be highly energy effective in full-scale MBRs (Wu and He, 2012). Ndinisa (Ndinisa et al., 2006) reported that the higher gas flow rate is, the greater mixing or turbulence in the system and thus an improvement in flux will be. Nevertheless, high performance of permeate flux can be achieved even at low gas flow rates. Yeo (Yeo et al., 2007) reported that the fluctuations in the shear stress (characterized by the standard deviation) was a key factor in performance improvement for submerged hollow fiber MBR. Their study showed that similar rates of increase of TMP can be achieved by using up to 10 times less air if small bubbles were used at a higher frequency due to the fluctuations in the shear stress generated under this condition although smaller bubbles produced lower average shear stress. Furthermore, it is not even always the case that the higher air flow rate (higher shear stress) is accompanied by an increase in overall mitigation of membrane fouling as observed in experiment
(Park et al., 2005). Though the tangential shear-induced force can prevent large particles depositing on the membrane surface, it has a limited effect on preventing the deposition of smaller particles. As a result, fine particles are inclined to deposit on the membrane surface in high aeration intensities, which finally results in a more compacted sludge cake and a rapid decrease in permeate (Delgado et al., 2008; Jiang et al., 2007). Actually, an average shear stress of 0.6 Pa was reported in a successfully operated full-scale MBR plant which required much lower specific aeration demand compared to lab-scale MBR whose shear stress was higher (Amini et al., 2013; Liu et al., 2015). The alternating oxic/anoxic process with the automatic control of the intermittent aeration (IA) based on oxidation-reduction potential (ORP), $\mathrm{pH}$ and/or dissolved oxygen (DO) monitoring is a suitable and effective strategy to adopt. Such a process would also represent a viable solution for improving the efficiency of nutrient removal and reducing energy. Guadie investigated the effect of intermittent aeration cycle (IAC $=15$ / $45-60 / 60 \mathrm{~min}$ ) on nutrient removal and microbial community structure using a fluidized bed reactor-membrane bioreactor. This combo system performed optimum nutrient removal and hosted stable microbial communities at 45/15 min of IAC (Guadie et al., 2014). Nevertheless, comparing them with a continuous process using dedicated compartments, more attention with regards to over aeration needed to reduce the chances of unscheduled manual intervention, system management and biological phenomena optimization (Capodici et al., 2015; Judd, 2011). Cyclic aeration, the so called 'eco-aeration', developed by the membrane supplier (Zenon-GE) and based on an aeration on/off intervals of $10 \mathrm{~s} / 30 \mathrm{~s}$, could potentially save $50 \%$ of currently consumed energy and could interrupt the steady state which would develop with constant aeration allowing for better solids accumulation disruption (Buer and Cumin, 2010). The cyclic aeration strategies of Zenon-GE was adjusted to $10 \mathrm{~s} / 10 \mathrm{~s}$ and $10 \mathrm{~s} / 30 \mathrm{~s}$ resulting in anount of air demand reduction between 50\% and 75\% in another studies (Krzeminski et al., 2017; Lorain et al., 2010) tested a pilot scale MBR with sequenced aeration with cycles of $5 \mathrm{~s}$ on and $25 \mathrm{~s}$ off and a strategy of low aeration during filtration and high aeration during backwash. The sequenced aeration reduced the membrane aeration flows by nearly $50 \%$, whereas coupling of aeration with filtration/backwash cycles reduced the membrane aeration flows by another $12 \%\left(\mathrm{SAD}_{\mathrm{m}}\right.$ of $\left.0.19 \mathrm{~m}^{3} / \mathrm{m}^{2} \mathrm{~h}\right)$. As can be seen, the ratios and durations of the time-on and time-off is the key factor for cyclic aeration, and if the dissolved oxygen (DO) at a certain ratio and duration is sufficient for carbonization and nitrification. However, numerical studies in this area are silent to the best of our knowledge, and it can be very exhausted if it is determined experimentally for various aeration flow rates and configurations.

In this study, the impacts of membrane module configuration and cyclic aeration on membrane shear stress and nitrogen removal in the AEC-MBRs for its scaling-up was studied by using an integrated CFD model. Sensitivity analysis of both lateral and vertical configuration design on hydrodynamics were carried out to better understand and guide the scaling-up of AEC-MBRs. Cyclic aeration modes with different duration considering membrane shear stress and DO concentration were tested to give insight to the better determination of this strategy. Experiments of the removal performance of pollutants (COD, total nitrogen, etc.) were conducted for the evaluation and finally implementation of full scale AEC-MBRs.

\section{Materials and methods}

\subsection{Experimental setup and operational conditions}

For the lab-scale AEC-MBR, a clapboard with two connecting holes is placed in a single tank, separating it into two units with a volume of $60.0 \mathrm{~L}$ and $30.0 \mathrm{~L}$, respectively. Membrane module packed five flat sheet membranes (SINAP Membrane Tech Co., Ltd., Shanghai) with working area of $0.5 \mathrm{~m}^{2}$ and design flux of $20.0 \mathrm{~L} \mathrm{~m}^{-2} \mathrm{~h}^{-1}$ was placed in the middle of the membrane unit. The air diffused from the sparger at 


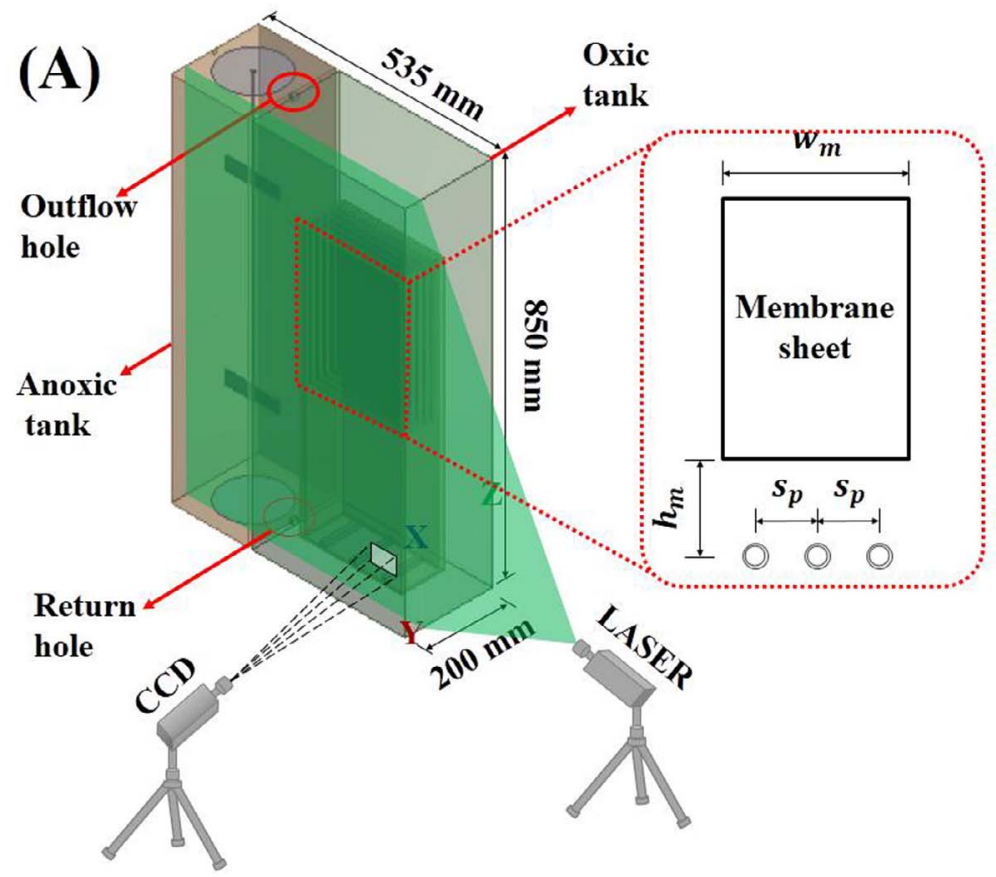

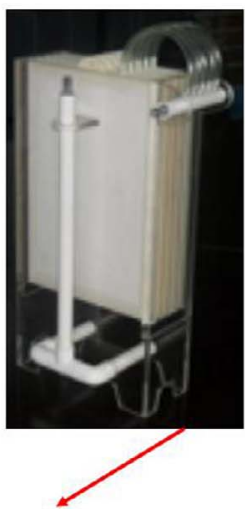

Membrane module

(B)
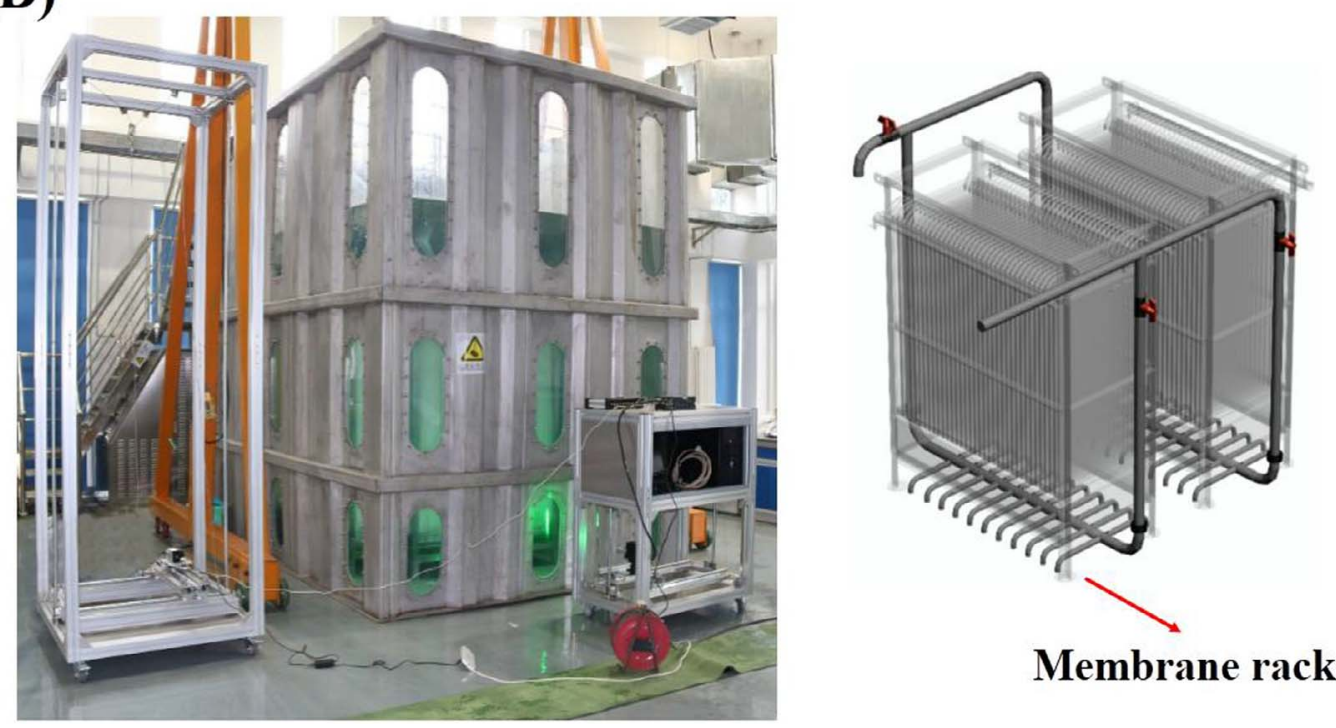

Fig. 1. Configuration of the lab-scale AEC-MBR (A) and full-scale MBR system (B).

Table 1

Design variables of different scale MBRs tested for sensitivity analysis of hydrodynamics.

\begin{tabular}{|c|c|c|c|c|}
\hline \multirow[t]{2}{*}{ Items } & \multicolumn{2}{|l|}{ Lab-scale } & \multicolumn{2}{|l|}{ Full-scale } \\
\hline & Control variable value & Stepping variable values & Control variable value & Stepping variable values \\
\hline Aerator tube interval & 116.7 & 70 & 180 & 150 \\
\hline Module location height & 150 & 100 & 200 & 100 \\
\hline Aerator-sheet distance & 300 & 150 & 400 & 300 \\
\hline Safety water depth & 200 & 100 & 500 & 400 \\
\hline Flat sheet spacing & 10 & 7 & 10 & 7 \\
\hline Flat sheet orientation & Perpendicular & Parallel & Perpendicular & Parallel \\
\hline Encircled baffle & Yes & No & Yes & No \\
\hline
\end{tabular}


the bottom of the membrane module generated the flow of mixed liquor. The aeration driven mixed liquor was recycled externally between the two units through the two connecting holes located at the clapboard and was recycled internally between the riser and downcomer of the membrane tank. The aeration diffusers were perpendicular to the membrane surfaces (Fig. 1(A)). The geometry of commercial membrane module (Zizheng Environment Tech Co., Ltd., Shanghai) used for CFD simulation of full-scale MBR with a single tank $(2.36 \mathrm{~m} \times 1.39 \mathrm{~m} \times 4.40 \mathrm{~m})$ is indicated Fig. 1(B). It consists of two modules aligned vertically with 80 membrane sheets per each module and with a total membrane area of $144 \mathrm{~m}^{2}$. To reduce computational burden for full-scale MBR, symmetric boundaries are utilized considering the physical dimensional symmetric layout. In this case, quarter of the physical model is generated and two perpendicular symmetric planes in vertical are established through the center of the tank. In order to evaluate the performance of different cases, seven design variables, including flat sheet design and aeration design, on the hydrodynamics and aeration patterns of lab-scale and full-scale MBR were compared (Table 1$)$. The relative sensitivity $(R S)$ was evaluated using Eq. (1), where, $y$ and $\Delta y$ are the simulation output variables and their variation; $x$ and $\Delta x$ are the model input variables and their variation. Shear stress (model output) responses to the variation of each input factor (variable) (Table 1). The variable value and stepping sizes of each variable were referred to the empirical value in lab-scale MBR and full-scale MBR, respectively.

$R S=\frac{\Delta y / y}{\Delta x / x}$

$R S$ analysis eliminates the influence of unit and absolute values of different input variables by considering their relative variations only, as a result, the magnitude of $R S$ associated with each parameter is comparable. The evaluation criteria of $R S$ value are listed below.

$|R S|<0.25$, the variable has negligible significant influence on a model output;

$0.25 \leq|R S|<1$, the variable is influential on a model output to a certain extent;

$1 \leq|R S|<2$, the variable is very influential on a certain model output.

The sludge used in laboratory AEC-MBR was inoculated from a wastewater treatment plant (WWTP) with a process of anoxic-anaerobic-oxic-MBR in Beijing and the initial concentration of mixed liquid suspended solids (MLSS) was $3000 \mathrm{mg} / \mathrm{L}$. The synthetic wastewater was pumped from the feed tank into the anoxic unit by a peristaltic pump (YZ1515X-A, LONGER, China) controlled by a liquid level gauge to get a stable influence flux in the lab-scale AEC-MBR. The ingredient of the synthetic wastewater including $400 \mathrm{mg} / \mathrm{L}$ glucose (approximately $360 \mathrm{mg} / \mathrm{L}$ COD), $200 \mathrm{mg} / \mathrm{L} \mathrm{CH}_{3} \mathrm{COONa}$ (approximately $190 \mathrm{mg} / \mathrm{L}$ COD), $191 \mathrm{mg} / \mathrm{L} \quad \mathrm{NH}_{4} \mathrm{Cl}$ (50 mg/L ammonium), $35 \mathrm{mg} / \mathrm{L} \mathrm{KH}_{2} \mathrm{PO}_{4}$ ( $8 \mathrm{mg} / \mathrm{L}$ total phosphorus), $100 \mathrm{mg} / \mathrm{L} \quad \mathrm{MgSO}_{4} \cdot 7 \mathrm{H}_{2} \mathrm{O}, \quad 50 \mathrm{mg} / \mathrm{L}$ $\mathrm{CaCl}_{2} \cdot 2 \mathrm{H}_{2} \mathrm{O}, 250 \mathrm{mg} / \mathrm{L} \mathrm{NaHCO}{ }_{3}\left(300 \mathrm{mg} / \mathrm{L} \mathrm{CaCO}{ }_{3}\right.$ alkalinity) and $1 \mathrm{~mL}$ of trace element solution per liter wastewater. The trace element composed of $1500 \mathrm{mg} / \mathrm{L} \quad \mathrm{FeCl}_{3} \cdot 7 \mathrm{H}_{2} \mathrm{O}, 150 \mathrm{mg} / \mathrm{L} \mathrm{H}_{3} \mathrm{BO}_{4}, \quad 30 \mathrm{mg} / \mathrm{L}$ $\mathrm{CuSO}_{4} \cdot 5 \mathrm{H}_{2} \mathrm{O}, \quad 180 \mathrm{mg} / \mathrm{L} \quad \mathrm{KI}, \quad 120 \mathrm{mg} / \mathrm{L} \quad \mathrm{MnCl}_{2} \cdot 4 \mathrm{H}_{2} \mathrm{O}, \quad 60 \mathrm{mg} / \mathrm{L}$ $\mathrm{Na}_{2} \mathrm{MoO}_{4} \cdot 2 \mathrm{H}_{2} \mathrm{O}, 120 \mathrm{mg} / \mathrm{L} \mathrm{ZnSO}_{4} \cdot 7 \mathrm{H}_{2} \mathrm{O}, 150 \mathrm{mg} / \mathrm{L} \mathrm{CoCl}_{2} \cdot 6 \mathrm{H}_{2} \mathrm{O}$ and $10,000 \mathrm{mg} / \mathrm{L}$ EDTA. Detailed information of configuration and operation is referred to (Yang et al., 2016a). The feed water for the pilot-scale study was a mixture of domestic wastewater and coal mine drainage at a proportion of around 5:1 $(v / v)$ and with a $\mathrm{BOD}_{5} / \mathrm{COD}$ ratio of 0.58 (Table 2).

\subsection{Sampling and analysis}

The Particle Image Velocimetry (PIV, EM3-03M1500, Micro Vec Co., LTD) measurement was adopted to validate the CFD simulation of velocity patterns in AEC-MBR. Rheology of activated sludge samples from the AEC-MBR was measured by a Haake RS6000 Rheometer ${ }^{\circledast}$ (Thermo Scientific, USA). Detailed procedures of these two measurements are referred to (Yang et al., 2016a). All relative errors less than $5 \%$ suggested that the model provided a good description of the flow behavior. DO concentrations in different locations in oxic unit and anoxic unit were measured with a fluorescence DO meter (Multi 3410, WTW Co Ltd, German) in state stages (Fig. 1(A)). The measured data was then used to calibrate the coefficients involved in $k_{L}$ a. To consider the oxygen consumption by microbes, the dynamic oxygen uptake rate (OUR) was used as a sink term in the mass balance equation (Guo et al., 2013). Denitrification rate measurement was carried out to evaluate the denitrifiers' activity as follows: $1100 \mathrm{~mL}$ of bulking liquid was taken out from the anoxic unit and completely mixed, $100 \mathrm{~mL}$ of bulking liquid was used for MLVSS determination. The extra bulking liquid was settled for $30 \mathrm{~min}$, after which the supernatant was withdrawn. Then the bulking liquid was charged with nitrogen gas and was kept suspended on a magnetic stirrer. The raw sewage was added with the same volume of the withdrawn supernatant. And certain amount $\mathrm{KNO}_{3}$ solution and Allylthiourea (ATU) were added to make a concentration of $40.0 \mathrm{mg} / \mathrm{L}$ total nitrogen (TN) and $10.0 \mathrm{mg} / \mathrm{L}$ ATU, respectively. The first sample was taken immediately and filtered, and then samples were taken and filtered at the time of $2 \mathrm{~min}, 4 \mathrm{~min}, 6 \mathrm{~min}, 8 \mathrm{~min}, 10 \mathrm{~min}, 15 \mathrm{~min}$, $20 \mathrm{~min}, 25 \mathrm{~min}, 30 \mathrm{~min}, 35 \mathrm{~min}, 40 \mathrm{~min}, 45 \mathrm{~min}, 50 \mathrm{~min}, 55 \mathrm{~min}$, $60 \mathrm{~min}, 70 \mathrm{~min}, 80 \mathrm{~min}, 90 \mathrm{~min}, 100 \mathrm{~min}, 110 \mathrm{~min}$ and $120 \mathrm{~min}$, respectively. Nitrate was measured after all samples were collected at once. Denitrification rate was finally obtained through the linear regression. The COD, ammonia, nitrate, nitrite and total nitrogen were measured according to standard methods (APHA, 2005) within one week after the sample collecting.

\subsection{CFD modelling}

\subsubsection{Model development}

\section{(1) Governing equations}

The three phases (air-water-sludge) were simplified as the gas-liquid two phases with the liquid viscosity property modified by a sludge rheological model in this study (Yang et al., 2016b). The steady-state and transient simulations of multiphase flow were described by EulerEuler model which was commonly used for wastewater treatment system involving large numbers of activated sludge, bubbles in sewage water phase due to its higher resolution and flexibility for further model development (Wang et al., 2009; Wang et al., 2011). Each phase in the model is described as interpenetrating continua incorporates the concept of phasic volume fraction, which represents the space occupied by each phase, and the laws of conservation of mass and momentum are

Table 2

Composition of the feed water and yield water quality measured in the pilot-scale AEC-MBR.

\begin{tabular}{|c|c|c|c|c|c|c|c|}
\hline Items & Water flow $\left(\mathrm{m}^{3} / \mathrm{d}\right)$ & COD (mg/L) & BOD (mg/L) & Ammonia (mg/L) & $\mathrm{TN}(\mathrm{mg} / \mathrm{L})$ & $\mathrm{TP}(\mathrm{mg} / \mathrm{L})$ & $\mathrm{pH}$ \\
\hline Influent & $1.6-2.0$ & $62.4-403.6$ & $41.1-218.2$ & $13.3-34.1$ & $14.9-57.5$ & $0.6-3.9$ & 6.3 \\
\hline Effluent & $1.6-2.0$ & $0.0-12.7$ & $0-2$ & $0.0 \pm 0.9$ & $7.4-22.2$ & $0.1-1.4$ & 7.4 \\
\hline Removal ratio (\%) & - & $80.3 \pm 12.5$ & $97.0 \% \pm 3.3$ & $97.8 \pm 3.0$ & $47.5 \pm 14.2$ & $60.8 \pm 11.3$ & - \\
\hline
\end{tabular}


satisfied by each phase individually. In the model framework, all phases shared a single pressure according to their respective volume fractions proportionally while momentum and continuity equations are solved for each phase. The main interaction between each phase is described by a drag coefficient function, which can be chosen from the drop-down list embedded in FLUENT or modified through user-defined functions considering the multiphase regimes. The Schiller and Naumann model, which is available and is acceptable for general use for all fluid-fluid pairs of phases, is applied in this study (ANSYS, 2014). To improve convergence behavior, the model was set up and solved using the mixture model (with slip velocities) instead of the Eulerian model at first. And then the calculation was continued by turning on the EulerEuler model with the mixture model solution as an initialization. To describe the effects of turbulent fluctuations of velocities and scalar quantities in multiphase, the RNG $k-\varepsilon$ mixture turbulence model was chosen as the closure model (ANSYS, 2014).

\section{(2) Species transport equations}

The DO transformation and distribution in the AEC-MBR was predicted by solving the advection-dispersion species transport equation extended with an oxygen mass transfer (OTR) sub-model and an oxygen uptake sub-model. The oxygen transfer rate (OTR) corresponding to source term in species transport equation is referred to previous work (Yang et al., 2016a). To reduce the computational burden, reduced order liner description of bio-kinetics developed in previous work was applied (Yang et al., 2016a). In this model framework, the OUR corresponding to sink term in species transport equation is estimated by a simplified ASM model (Julien et al., 1999; Littleton et al., 2007) and is expressed as,

OUR $_{\text {Oxic }}=$ OUR $_{\text {Cons }}$

$\mathrm{OUR}_{\text {Anoxic }}=k \mathrm{OUR}_{\mathrm{Cons}}\left(\frac{\mathrm{S}_{\mathrm{O}}}{\mathrm{K}_{\mathrm{OH}}+\mathrm{S}_{\mathrm{O}}}\right)$

Where $\mathrm{K}_{\mathrm{OH}}\left(\mathrm{mg} \mathrm{L}^{-1}\right)$ is the half saturation constant of oxygen, $\mathrm{S}_{\mathrm{O}}$ ( $\mathrm{mg} \mathrm{L}^{-1}$ ) is the concentration of dissolved oxygen, OUR $\mathrm{Oxic}$ $\left(\mathrm{mg} \mathrm{L}^{-1} \mathrm{~h}^{-1}\right)$ and OUR Anoxic $\left(\mathrm{mg} \mathrm{L}^{-1} \mathrm{~h}^{-1}\right)$ are the oxygen uptake rates in oxic unit and anoxic unit, respectively, OUR $\mathrm{OUn}_{\mathrm{Cons}}\left(\mathrm{mg} \mathrm{L}^{-1} \mathrm{~h}^{-1}\right)$ is the constant oxygen uptake rate to be identified, $k$ is the coefficient of OUR in anoxic unit.

A CFD simulation with the reduced order liner description of oxygen uptake rate was thus carried out for the modelling of the hydrodynamics and DO distribution. The coefficients involved in Eq. (4) were then calibrated according to the measured data, which give the simulation of the DO concentration a good match to the experimental data at different positions in the AEC-MBR.

\subsubsection{Boundary conditions}

The membrane surfaces were treated as impermeable, stationary walls, which were free slip for air and no slip for liquid (Ndinisa et al., 2006; Yang et al., 2012). No inlet or outlet boundary conditions for liquid phase were set because the effects of influent and effluent on the flow pattern were ignored and the oxygen consumption was considered by the introduction of OUR rather than by the dynamic consumption of substrates added in the influent. The air diffuser, through which the air entered the membrane tank, was treated as a plain surface with an inlet flow rate of air equivalent to superficial gas velocity. The bubble size are assumed to be constant and a constant diameter of $5 \mathrm{~mm}$ and $10 \mathrm{~mm}$ are applied respectively for lab-scale and full-scale MBRs for all simulations. The recommended aeration intensity given by the manufacturers $\left(1 \mathrm{~m}^{3} / \mathrm{h}\right.$ for lab-scale MBRs and $43 \mathrm{~m}^{3} / \mathrm{h}$ for full-scale MBRs) were employed constantly throughout this work. This is to provide a basis for the comparison of the effect of different variables on hydrodynamics. In turn, the optimized design under this aeration condition is expected to be optimized in other aeration intensities. So a reduction of power consumption can be expected by reducing the aeration intensity or applying cyclic aeration with lower time-on/time-off ratios given an optimized design configuration. A degassing boundary condition was specified for the water-air surface. No slip boundary conditions were assigned for all other walls. The roughness constant and the roughness height at the no slip walls were default. The rotation by the submerged impeller in the anoxic unit was treated as a multiple reference frame. Residuals criteria of $1 \times 10^{-7}$ was used for convergence of equations involving species transport, and the default residuals criteria of $1 \times 10^{-3}$ was used for convergence of equations involving mass, momentum, $\mathrm{k}$ and epsilon, etc. Data of flow velocity and DO concentration at a cross section were also monitored to make sure the simulation reached a steady state.

\section{Results and discussion}

\subsection{Comparison of flow pattern}

\subsubsection{Liquid velocity of the riser}

The gas/liquid two-phase flow was mostly employed in membrane bioreactors due to its potential for membrane scouring to slow down membrane fouling and enhance flux (Wibisono et al., 2014). In most cases, a higher circulation flow rate is more efficient for membrane fouling control due to the higher shear forces generated. Taking the form of the airlift loop configuration, the submerged AEC-MBR with an all-around baffle module established an obvious circulation loop between riser and downcomer (Fig. 2A). With larger cross-sectional area and less air volume fraction, the downcomer was observed having a much smaller liquid velocity than that in the riser (Fig. 2B). The membrane sheets were installed in the riser zone where higher bulk liquid flow rate can be expected (Fig. 2B). In fact, a lower ratio of crosssectional area of the riser to that of the downcomer $A_{r} / A_{d}$ would generate a higher liquid velocity of the riser, $\mathrm{U}_{\mathrm{Lr}}$. Yan reported that the average riser velocity increased with decrease of $A_{r} / A_{d}$ when it was lower than 0.75 , and a ratio of 0.17 was considered to be favorable in their bench-scale study with only one membrane sheet installed (Yan et al., 2016). However, the increase of downcomer area results in higher local resistance loss at the bottom connecting section, which will finally decrease the overall recirculation rate due to the energy dissipation (Chisti et al., 1988, 1995). This inherent contradiction appears to be improved in full-scale MBRs in two aspects: larger packing density and bigger module size. For a tank with a membrane module of fixed size, the $A_{r} / A_{d}$ will decrease with the membrane packing density because the membrane sheet itself occupies the cross area in the riser. For a certain $A_{r} / A_{d}$, the bigger lateral module size is, the narrow the downcomer area will be. Therefore, this somehow explained the higher $\mathrm{U}_{\mathrm{Lr}}$ achieved in full-scale MBR which had an $\mathrm{A}_{\mathrm{r}} / \mathrm{A}_{\mathrm{d}}$ of 0.113 compared to that of 0.220 for lab-scale MBR in this case. But more importantly, the treatment capacity will increase dramatically with the module size and packing density, $14.7 \%$ higher shear stress was achieved with a specific aeration demand with respect to membrane area $\left(\mathrm{SAD}_{\mathrm{m}}\right)$ of 0.3 for the full-scale MBR $\left(14.43 \mathrm{~m}^{3}\right)$, which was $85 \%$ lower than that for the lab-scale MBR $\left(0.6 \mathrm{~m}^{3}\right)$ in this study. The extension of module size in vertical also played a vital role in $\mathrm{U}_{\mathrm{Lr}}$ in the scale-up of MBRs and the liquid velocity was very high all along the membrane sheets for fullscale study. Chist conducted a series experiments to characterize the liquid velocity of riser in 13 different airlift reactors with reactor height range of 1.36-8.5 m and riser-to-downcomer cross-sectional area ratios in the range of 0.5-9.1. Their results indicated that the $U_{\mathrm{Lr}}$ was proportional to square root of gas-liquid dispersion height, $h_{D}$, according to the energy balance analysis (Chen et al., 2016). Nevertheless, the higher the $h_{D}$, the higher reactor headspace pressure, and a $h_{D}$ of $2-5 m$ is usually on safe ground for full-scale MBRs (Judd, 2011).

\subsubsection{Sludge rheology}

The sludge rheology was also observed to have an obvious effect on 

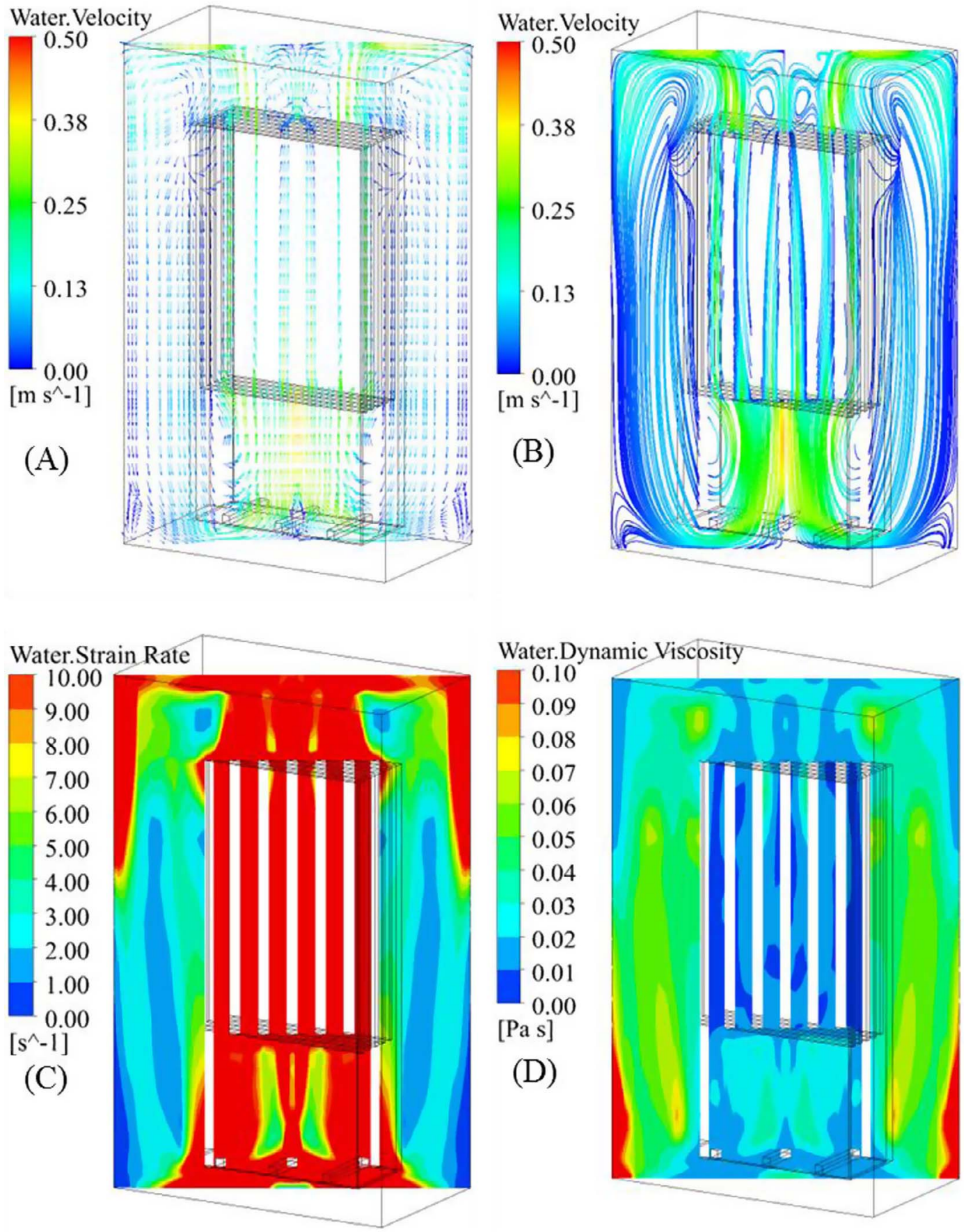

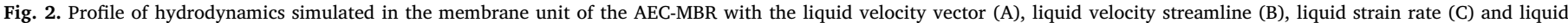
dynamic viscosity (D)

the flow pattern. The liquid strain rate was highly negatively correlated to the local viscosity $(p \approx 0.0000)$ which was dynamic due to the sludge rheological property (Fig. 2C and D), i.e., where the strain rate was high, the local viscosity was low and vice versa. With the consideration of sludge rheology, the flow pattern and liquid velocity were different from the situations in which the apparent sludge viscosity were applied (Busch et al., 2007; Tang and Zhang, 2014). The liquid velocity of pure water was highest and then followed by the bulk liquid with sludge rheology consideration and bulk liquid with apparent viscosity of $30 \mathrm{mPa}$. The viscosity with rheology consideration was variable and became much higher at local areas with small shear rate
(Fig. 2D). The high viscosity produced a high energy dissipation due to the high force of friction generated. More kinetic energy was thus converted to internal energy and led to a velocity decrease (Fig. 2B). The property of sludge rheology can be an important factor on oxygen mass transfer due to the impact on liquid velocity and can be more profound for full-scale MBRs in which larger dead zone occurs and thus was taken into consideration for DO simulation. 


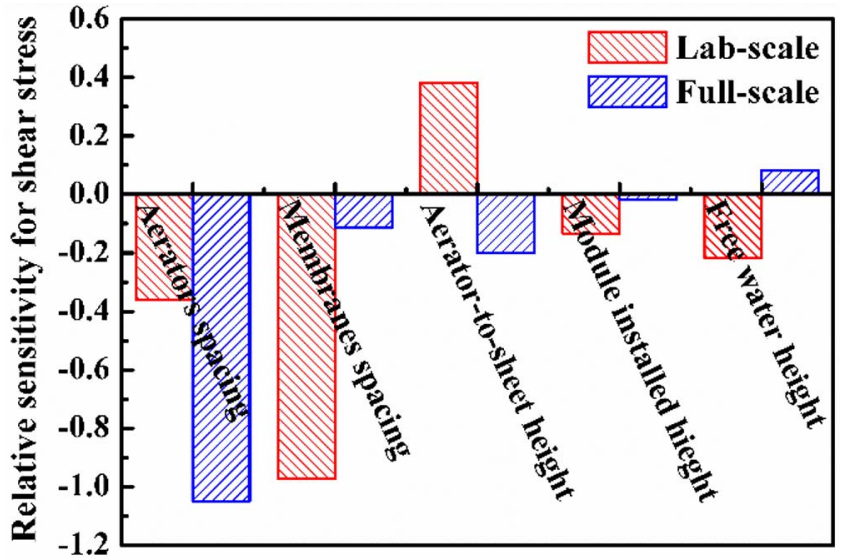

Fig. 3. Sensitivity analysis of design variables on shear stress on membranes simulated in lab-scale and full-scale MBRs.

\subsection{Effects of horizontal design variables on hydrodynamics}

\subsubsection{Aerators spacing and orientation}

The uneven distribution of shear stress was often observed whether the aeration tube was positioned perpendicular (Liu et al., 2015) or parallel (Yan et al., 2015) to the membrane sheets. A proper interval of aeration diffusers is one of the most simple and efficient ways for a high
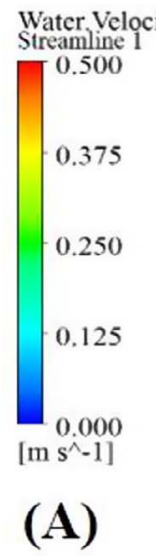

\section{())}
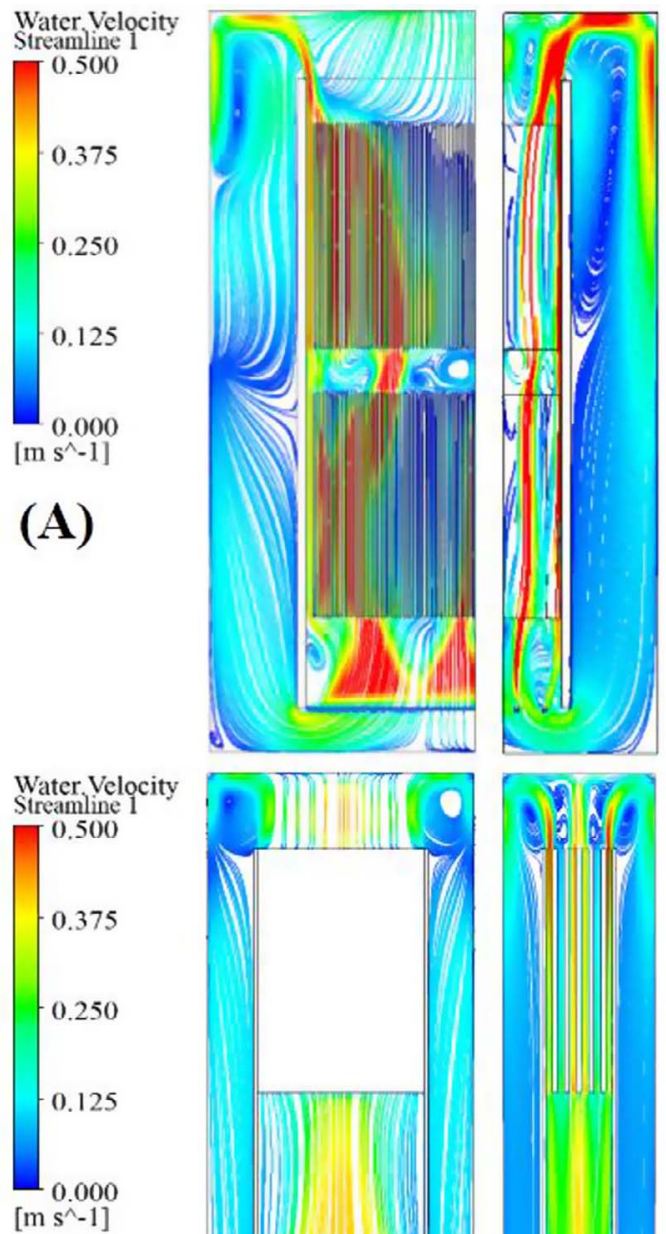

(C)

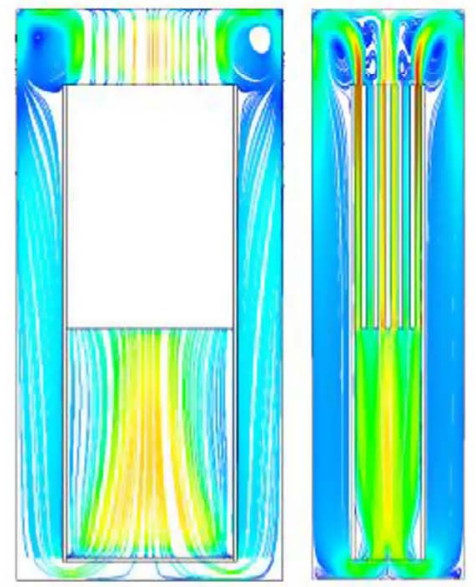

Table 3

Average shear stress on membranes at stepping groups and its relative change to control group in lab-scale and full-scale MBRs.

\begin{tabular}{|c|c|c|c|c|}
\hline \multirow[t]{2}{*}{ Design variables } & \multicolumn{2}{|l|}{ Lab-scale } & \multicolumn{2}{|l|}{ Full-scale } \\
\hline & $\begin{array}{l}\text { Shear stress at } \\
\text { stepping } \\
\text { groups }(\mathrm{Pa})\end{array}$ & $\begin{array}{l}\text { Relative } \\
\text { change (\%) }\end{array}$ & $\begin{array}{l}\text { Shear stress at } \\
\text { stepping } \\
\text { groups }(\mathrm{Pa})\end{array}$ & $\begin{array}{l}\text { Relative } \\
\text { change (\%) }\end{array}$ \\
\hline Aerators spacing & 1.224 & 14.39 & 1.445 & 17.48 \\
\hline $\begin{array}{l}\text { Module installed } \\
\text { height }\end{array}$ & 1.118 & 4.49 & 1.24 & 0.81 \\
\hline $\begin{array}{l}\text { Aerator-to-sheet } \\
\text { height }\end{array}$ & 0.894 & -16.45 & 1.292 & 5.04 \\
\hline $\begin{array}{l}\text { Safety water } \\
\text { depth }\end{array}$ & 1.187 & 10.93 & 1.21 & -1.63 \\
\hline $\begin{array}{r}\text { Membranes } \\
\text { spacing }\end{array}$ & 1.486 & 38.88 & 1.281 & 4.15 \\
\hline $\begin{array}{l}\text { Aerator } \\
\quad \text { orientation }\end{array}$ & 1.191 & 11.31 & 1.312 & 6.67 \\
\hline Encircled baffle & 0.861 & -19.53 & 1.148 & -6.67 \\
\hline
\end{tabular}

and even shear stress distribution (Li et al., 2011). The distribution of the air volume fraction got more even along with the decrease of $s_{\mathrm{p}}$ in the lab-scale study. The shear stress increased by $18.8 \%$ while the standard deviation of shear stress decreased by $56.0 \%$ from $s_{p}$ of $1 / 1$ to $1 / 5$. This effect was more profound in full-scale MBRs where the aerators were arranged with much larger interval because a reduction

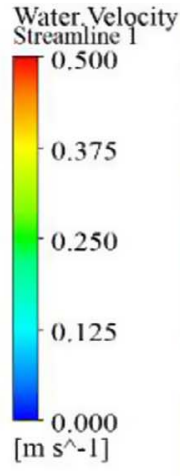

(B)
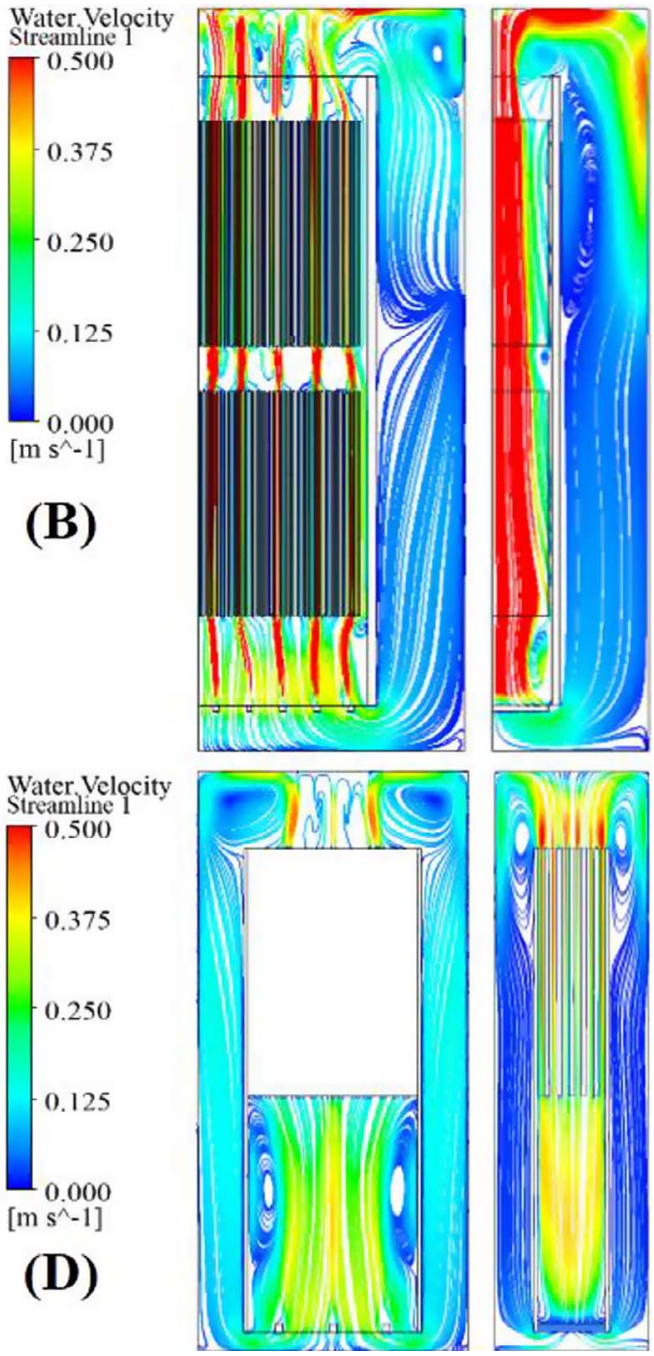

Fig. 4. Streamline profile at different aerator orientations simulated in full-scale MBR (A: perpendicular and B: parallel) and small-scale MBR (C: perpendicular and D: parallel). 
of aerators' interval could be more significant to the evenness of air volume fraction distribution (Fig. 3). When the aeration tubes were perpendicular to the membrane sheets, larger eddies were observed at the bottom and top of membrane sheets both for lab-scale and full-scale MBRs, which were expected to cause more energy dissipation. The eddies occurred due to the higher liquid velocity difference between the air flow path to the boundary such as the baffle and rigid lid in the riser and tank wall in the downcomer. The situation improved when the aeration tubes were parallel positioned to the membrane sheets where the liquid velocities along the air flow path were lower but were more homogeneously distributed between the membranes spacing (Fig. 4). The shear stress were $11.3 \%$ and $6.7 \%$ higher when the aeration tubes were parallel positioned to the membrane sheets for lab-scale and fullscale MBRs, respectively (Table 3). Therefore, for the perpendicular situation, it seems that the numbers of aerator tubes should be added to reduce the eddy and equalize the membrane scouring before the average shear stress decrease too much. For the parallel situation, the optimum design seems to have one aeration tube for each of the membrane sheet.

\subsubsection{Membranes spacing}

Though the shear stress of full-scale MBRs showed a higher sensitivity to the aerators' spacing, it was much less sensitive to the membrane spacing (Fig. 3). To be specific, the average shear stress increased only by $4.2 \%$ for full-scale MBR, comparing to $38.9 \%$ for lab-scale one by decreasing the membrane space from $10 \mathrm{~mm}$ to $7 \mathrm{~mm}$ (Table 3). The reason could be the energy dissipation at the connection zone of the two module layers, where large vortex formed due to the interrupt of the top and the bottom of the membrane module at down layer and top layer, respectively (Fig. 4). The energy dissipation at this zone increased with the decrease of membrane spacing and this partially counteracted the liquid velocity acceleration by decreasing $A_{r} / A_{d}$. Therefore, it is better to have only one layer of membrane module with longer membrane sheet instead of multi layers discretely erected.

\subsubsection{Role of encircled baffle}

In baffled MBRs, the baffles divide the membrane tank into riser zone and downcomer zone, create an internal circulation and a regular cross flow on the membrane surfaces due to the difference in gas holdup and bulk density in different zones. Baffles were proved to useful for the reduction of membrane fouling for lab-scale MBRs both in simulations and experiments (Krzeminski et al., 2017; Yan et al., 2016). The results of lab-scale study in this study were consistent with the above observations. The average shear stress on membranes for lab-scale MBR with baffles was $24.3 \%$ higher than that without baffles. The full-scale MBRs without fully encircled baffle, however, may stands for a chance because the intense interactions of bulk liquid between riser and downcomer creates some turbulence which is considered to be benefit for cake layer mitigation. Unfortunately, the shear stress on membrane of the full-scale MBR with baffle was also $7.1 \%$ higher in this study (Table 3). The large eddies occurred mainly in the downcomer didn't enhance the membrane scouring in the riser but caused rapid energy dissipation. In this case, many small eddies or vortex introduced to the riser by using turbulence promoters or using baffles with different shapes may have positive effect on fouling control and will be reported in future work.

\subsection{Effects of vertical design variables on hydrodynamics}

\subsubsection{Distance from aerators to bottom edge of membrane}

The distance from the aerator to the bottom edge of membrane was a very important design variables for lab-scale MBRs (Zhang et al., 2013). In this study, the distance from aerators to bottom edge of membrane, $\mathrm{h}_{\mathrm{m}}$ was adjusted at a range of $0-450 \mathrm{~mm}$ for lab-scale MBRs. The simulations showed that the average shear stress was increased with the $h_{m}$ while the standard deviation of shear stress decreased, which finally equalized and enhanced the shear stress on different membrane sheets at $h_{m}$ of $300-450 \mathrm{~mm}$. This is consisted with most of the results for lab-scale studies (Liu et al., 2016; Yan et al., 2015). The maximum average shear stress for the optimized membrane module configuration at $\mathrm{h}_{\mathrm{m}}$ of $450 \mathrm{~mm}$ is $1.49 \mathrm{~Pa}, 65.6 \%$ higher than that of $\mathrm{h}_{\mathrm{m}}$ of $0 \mathrm{~mm}$. It could be concluded that the increase of $h_{m}$ is preferable for fouling control in lab-scale MBRs. However, the comparison results were different for full-scale MBRs when the $h_{m}$ confined at $300 \mathrm{~mm}$ and $400 \mathrm{~mm}$. The shear stress showed less sensitivity to the $h_{m}$ and the average shear stress even slightly decreased by $4.8 \%$ when increase $h_{m}$ from $300 \mathrm{~mm}$ to $400 \mathrm{~mm}$ (Table 3). It was easy to understand because the height of the gas-liquid dispersion of full-scale MBR was much greater than that of the lab-scale one. The fluid flow can fully develop in the airlift process and the relative change for full-scale (100/4400) was too small comparing with lab-scale $(150 / 1000)$ to make much difference in flow pattern. Therefore, the main consideration for full-scale MBR is to avoid stagnation in this zone and a height of $h_{m}$ at $75 \mathrm{~mm}$ to $150 \mathrm{~mm}$ is applicable for such a full-scale MBR.

\subsubsection{Height of membrane module positioned}

The local resistance loss at the bottom connecting section, e.g., the space between module and the bottom of the tank, is unavoidable but is improvable by adjusting the installed height of membrane module. The shear stress for full-scale MBR increased only by $0.8 \%$ by changing the height from $200 \mathrm{~mm}$ to $100 \mathrm{~mm}$. The shear stress over membranes for lab-scale showed much higher sensitivity to this height and increase by $4.5 \%$ by changing the height from $150 \mathrm{~mm}$ to $100 \mathrm{~mm}$ (Table 3). Taken the shape as a pipe, the connecting section can be seen as a pipe with elbow and diameter variation where the pipe diameter (space between module and the bottom of the tank) should be large enough to generate small liquid velocity for the reduction of energy dissipation for pipe with diameter variation but should be small enough to lower the local loss coefficient for an elbow pipe. Nevertheless, a shear stress respectively varied only by $0.8 \%$ or $4.5 \%$ by changing the space for full-scale and lab-scale MBRs didn't worth the efforts to find the optimum space.

\subsubsection{Safety water depth}

To protect the membranes from dry cracking at the low water level, a certain depth of safety water (water above the membrane module) is required. The liquid velocity in the safety water zone is usually large and this will unavoidably create eddies in this zone and the deeper the safety water, the larger the eddies. The average shear stress increased by $10.9 \%$ for lab-scale MBRs when the safety water depth decreased from $200 \mathrm{~mm}$ to $100 \mathrm{~mm}$. However, this was not as significant as the horizontal design variables did and the significance was even less in full-scale MBRs where the average shear stress increased only by $1.7 \%$ by changing the safety water depth from $400 \mathrm{~mm}$ to $500 \mathrm{~mm}$ (Table 3).

\subsection{MBR performance under cyclic aeration modes}

\subsubsection{Hydrodynamics after aeration stopping}

Transient simulations were conducted by stopping aeration from a steady state with $\mathrm{SAD}_{\mathrm{m}}$ of $2.0 \mathrm{~m}^{3} /\left(\mathrm{m}^{2} \mathrm{~h}\right)$ and $0.3 \mathrm{~m}^{3} /\left(\mathrm{m}^{2} \mathrm{~h}\right)$ for labscale and full-scale MBR, respectively. The liquid velocity dropped much faster and the flow completely stopped within few seconds in labscale MBR while the flow in full-scale MBR didn't fully stop even after $20 \mathrm{~s}$ (Fig. 5 (A)). The shear stress decreased linearly after stopping aeration and it was near to zero after about $6 \mathrm{~s}$ and $12 \mathrm{~s}$ for lab-scale and full-scale MBR, respectively. It is interesting that the shear stress and liquid velocity became zero almost at the same time in lab-scale MBR while there was a long tail for liquid velocity after the shear stress became zero in full-scale MBR. The possible explanation is that the tail end flow in full-scale MBR comes from the dissipation of large eddies which is not likely to occur in lab-scale MBRs or in the membranes' space in full-scale MBRs. These eddies are useless for membrane scouring but could be positive for the species transport and mass 

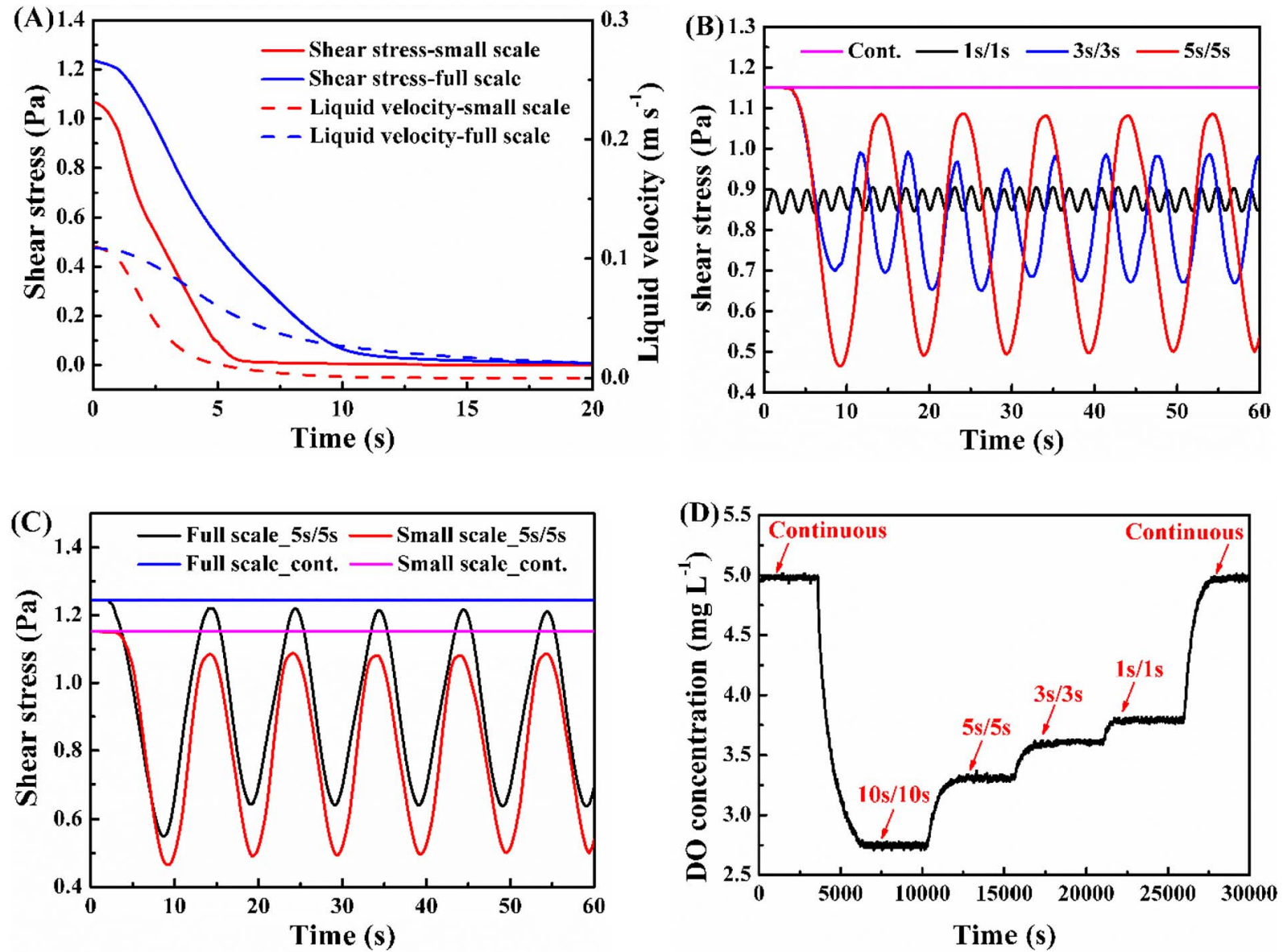

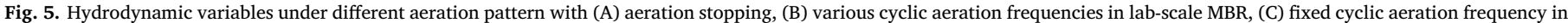
different scale MBRs and (D) DO concentrations measured in lab-scale MBR under different cyclic aerations.

transfer in full-scale MBRs especially when they are operated at cyclic aeration modes. The scouring on membranes can be roughly estimated from the observation of the flow behavior. It disappears at a half of the time when there is no obvious flow for full-scale MBRs while it ends only after the stop of flow for the lab-scale MBRs.

\subsubsection{Hydrodynamics under cyclic aeration modes}

Transient simulations were conducted to compare the hydrodynamics under cyclic aeration modes and continuous aeration mode. Sinusoidal curves of shear stress were created under cyclic aeration modes. The amplitude of shear stress on membranes enlarges with the cycle duration and the average shear stress at the on/off cyclic aeration of $1 \mathrm{~s} / 1 \mathrm{~s}, 3 \mathrm{~s} / 3 \mathrm{~s}$ and $5 \mathrm{~s} / 5 \mathrm{~s}$ reached by $76.0 \%, 70.8 \%$ and $69.3 \%$ of that at the constant aeration mode for lab-scale MBR (Fig. 5(B)). The decrease rate of shear stress in full-scale MBR was slower and a $74.4 \%$ of shear stress was reached at a shift frequency of $5 \mathrm{~s} / 5 \mathrm{~s}$ (Fig. $5(\mathrm{C})$ ). Though the overall fouling rate in the cycle aeration mode may higher than that in the constant aeration due to the decrease of overall shear stress, the higher percentage of reversible fouling can be expected for the cyclic aeration mode as reported by $\mathrm{Wu}$ (Wu and He, 2012). The reason are manifold: first, the cyclic aeration mode breeds larger sludge flocs. A short high aeration period could prevent the destruction of strong strength bonds within activated sludge flocs and the weak strength bonds damaged in the high aeration period could be recovered in the re-flocculation process in the non aeration period. Second, larger particles are more easily to deposit on membrane surfaces at the non aeration period, which could mitigate irreversible fouling by rejecting fine particles. From this perspective, a higher cycle duration with a larger amplitude of shear stress and a lower liquid velocity under non aeration period is more preferable. Otherwise, if only consider the magnitude of shear stress, it's better to keep it more than 0.6 Pa which is considered as an acceptable value for MBR maintenance (Liu et al., 2015). Then the cycle duration should not exceed $10 \mathrm{~s}$ in this study (Fig. 5(C)). Nevertheless, the energy consumption under the cyclic aeration modes is expected to reduce significantly, for instance, $50 \%$ of energy consumed by aeration machine can be expected in any cyclic aeration frequency in this study.

\subsubsection{DO concentration under cyclic aeration modes}

DO concentration is of great importance for AEC-MBRs in terms of carbonization and nutrients removal. The high rate of external circulated liquid flow with high DO concentration at a continuous aeration mode may disrupt the hypoxia condition in the anoxic tank. Under cyclic aeration modes, the DO concentration in membrane tank decreased substantially and it was even lower at a smaller aeration frequency (Fig. 5(D)). It is expected to be positive to maintain a low DO concentration in anoxic tank by lowering the external circulated liquid flow rate and the DO concentration in the liquid.

\subsection{Long term operation of AEC-MBRs}

\subsubsection{Long term operation of lab-scale AEC-MBR}

The DO distribution was simulated and measured in the AEC-MBR at $s_{p}$ of $1 / 3$ and $h_{m}$ of $300 \mathrm{~mm}$. With the bottom aeration, the liquid was lifted by the air drag and circulated internally between the inside and the outside of membrane module in the oxic tank (Fig. 6(A)). Because of the slip velocity between gas and liquid during this process, the oxygen was transferred from the gas phase to the liquid phase in the oxic unit especially in the riser zone where the volume of gas phase was high. Ammonia was turned to nitrate and nitrite by autotrophs and 

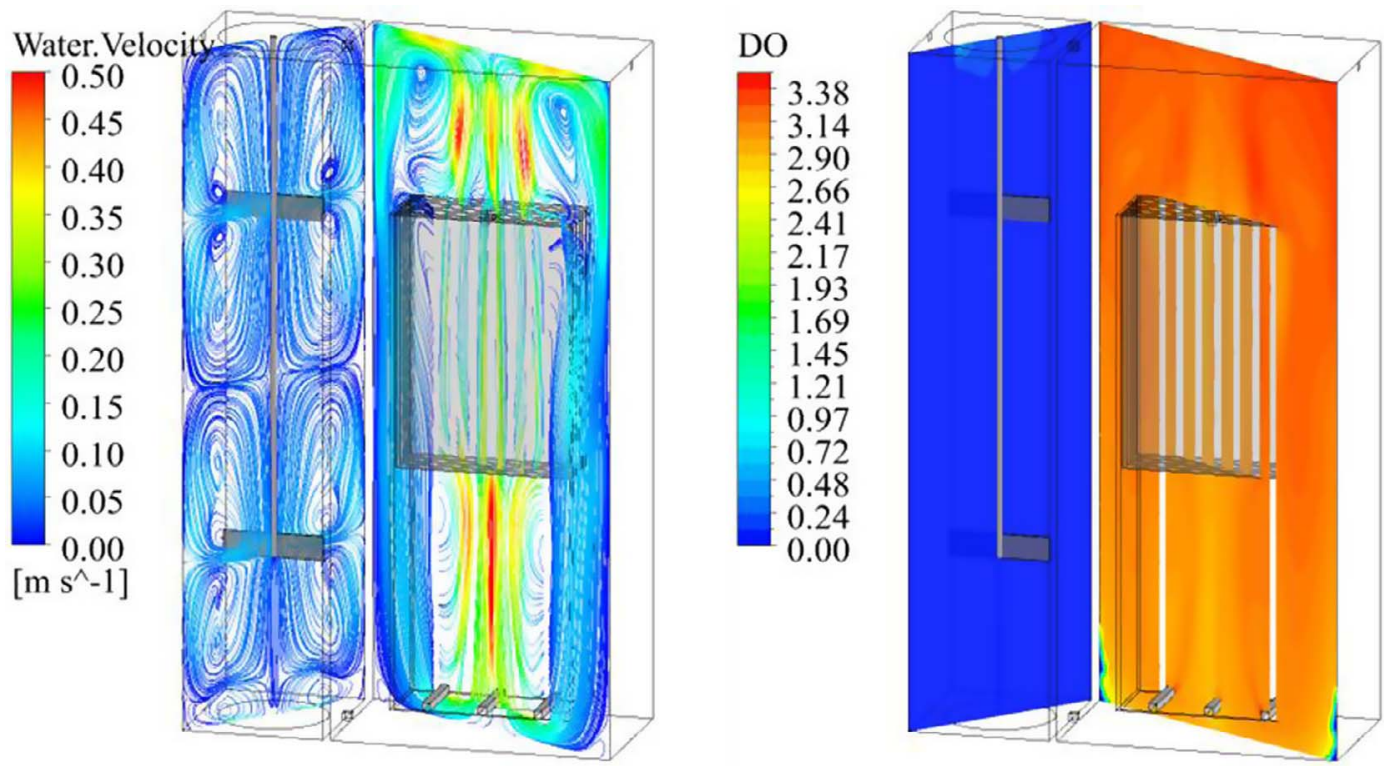

Fig. 6. Profile of water velocity streamline (left) and DO concentration (right) simulated in the optimized AEC-MBR at SAR 50.

heterotrophs in the oxic unit. Then the bulking liquid was recirculated to the anoxic unit where nitrate would be transferred to nitrogen gas by the denitrifiers (heterotrophs) given adequate substrates. As a species, the DO in the riser was transported to the downcomer. The DO concentration in the oxic unit reached an average value of $3.1 \mathrm{mg} \mathrm{L}^{-1}$ at SAR 50 (Fig. 6(B)). A non-uniform distribution of DO concentration in the oxic unit was found. The DO concentration on the top is a slight higher than that at the bottom. It can be attributed to the higher turbulent intensity on the top that enhances the mass transfer capacity. The DO concentration in the corner at the bottom is unexpected low. This can be explained by that the DO transported by diffusion rather than by convection to the corner where the eddy occurred was low (Fig. 6(A)). Without aeration, the DO resource in the anoxic unit was only the DO carried bulk liquid transported from the oxic unit during the external circulation. It was immediately consumed after entering the anoxic unit, and the average DO concentration in the anoxic unit was only $0.02 \mathrm{mg} \mathrm{L}^{-1}$ (Fig. 6(B)). The maximum denitrification rate of the activated sludge during this stage reached to $14.48 \mathrm{mg} \mathrm{g}^{-1}$ MLVSS $^{-1}$, which was considered as a high level to similar systems and suggested the high activity of denitrifiers in the anoxic unit (Han et al., 2005). The TN removal rate of the operated AECMBR was about $90 \%$ (decreased from $50 \mathrm{mg} / \mathrm{L}$ to at around $5.0 \mathrm{mg} / \mathrm{L}$ ) after 1 SRT ( $20 \mathrm{~d}$ ) due to the increase of biomass concentration and an obvious alternative oxic-anoxic environment.

\subsubsection{Long term operation of pilot-scale AEC-MBR}

A pilot-scale AEC-MBR with two parallel systems and a design capacity of $2.0 \mathrm{~m}^{3} / \mathrm{d}$ was built following the principle of geometric similarity of the lab-scale AEC-MBR. The on/off cyclic aeration of $5 \mathrm{~s} / 5 \mathrm{~s}$ was applied. During each cycle, the compressor worked continuously but a three-way solenoid valve was employed to switch the aeration from one system to another. The membranes were operated with an average flux of $16.3 \mathrm{~L} \mathrm{~m}^{-2} \mathrm{~h}^{-1}$ for more than three months before the transmembrane pressure reached at $30 \mathrm{kPa}$. The performance of the pilot-scale AEC-MBR was successful and the effluent quality meets the discharge standard of pollutants for municipal wastewater at Class 1-A of China (GB18918-2002) (Table 2). A solid conclusion of a reduction of $50 \%$ of aeration energy in Section 3.4.2 can be drawn after the conduction of the long term operation of this pilot-study.

\section{Conclusions}

The gap between lab-scale and full-scale AEC-MBRs is addressed in terms of module configuration and aeration patterns with CFD simulation. With lower $A_{r} / A_{d}$, higher $h_{D}$, and much larger treatment capacity, $14.7 \%$ higher shear stress was achieved for the full-scale MBR with only $15 \% \mathrm{SAD}_{\mathrm{m}}\left(0.3-2.0 \mathrm{~m}^{3} \mathrm{~m}^{-2} \mathrm{~h}^{-1}\right)$ of the lab-scale MBR. Cyclic aeration modes created a sinusoidal pattern of shear stress which created more fluctuations and was expected to reduce the irreversible fouling was proved to be a good strategy for significant energy reduction and pollutants removal for AEC-MBRs.

\section{Acknowledgements}

This work was financially supported by the Major Science and Technology Program for Water Pollution Control and Treatment of China (2015ZX07203-005) and the National Natural Science Foundation of China-Research (No. 51278483).

\section{Appendix A. Supplementary data}

Supplementary data associated with this article can be found, in the online version, at http://dx.doi.org/10.1016/j.biortech.2017.09.027.

\section{References}

Amini, E., Mehrnia, M.R., Mousavi, S.M., Mostoufi, N., 2013. Experimental study and computational fluid dynamics simulation of a full-scale membrane bioreactor for municipal wastewater treatment application. Ind. Eng. Chem. Res. 52, 9930-9939. ANSYS, 2014. FLUENT Theory Guide. Pera Global, United States of America.

APHA, 2005. Standard Methods for the Examination of Water and Wastewater, 21th ed. American Public Health Association, Washington, DC.

Berube, P.R., Lei, E., 2006. The effect of hydrodynamic conditions and system configurations on the permeate flux in a submerged hollow fiber membrane system. J. Membr. Sci. 271, 29-37.

Buer, T., Cumin, J., 2010. MBR module design and operation. Desalination 250, 1073-1077.

Buetehorn, S., Brannock, M., Le-Clech, P., Leslie, G., Volmering, D., Vossenkaul, K., Wintgens, T., Wessling, M., Melin, T., 2012. Limitations for transferring lab-scale microfiltration results to large-scale membrane bioreactor (MBR) processes. Sep. Purif. Technol. 95, 202-215.

Busch, J., Cruse, A., Marquardt, W., 2007. Modeling submerged hollow-fiber membrane filtration for wastewater treatment. J. Membr. Sci. 288, 94-111.

Cai, X., Zhang, M., Yang, L., Lin, H., Wu, X., He, Y., Shen, L., 2017. Quantification of interfacial interactions between a rough sludge floc and membrane surface in a membrane bioreactor. J. Colloid Interface Sci. 490, 710-718.

Capodici, M., Di Bella, G., Di Trapani, D., Torregrossa, M., 2015. Pilot scale experiment 
with MBR operated in intermittent aeration condition: analysis of biological performance. Bioresour. Technol. 177, 398-405.

Chen, J., Lin, H., Shen, L., He, Y., Zhang, M., Liao, B.Q., 2017. Realization of quantifying interfacial interactions between a randomly rough membrane surface and a foulant particle. Bioresour. Technol. 226, 220-228.

Chen, J., Zhang, M., Li, F., Qian, L., Lin, H., Yang, L., Wu, X., Zhou, X., He, Y., Liao, B.Q., 2016. Membrane fouling in a membrane bioreactor: high filtration resistance of gel layer and its underlying mechanism. Water Res. 102, 82-89.

Chisti, M.Y., Halard, B., Moo-Young, M., 1988. Liquid circulation in airlift reactors. Chem. Eng. Sci. 43, 451-457.

Chisti, Y., Wenge, F., Moo-Young, M., 1995. Relationship between riser and downcomer gas hold-up in internal-loop airlift reactors without gas-liquid separators. Chem. Eng. J. Biochem. Eng. J. 57, B7-B13.

Cui, Z.F., Chang, S., Fane, A.G., 2003. The use of gas bubbling to enhance membrane processes. J. Membr. Sci. 221, 1-35.

Delgado, S., Villarroel, R., González, E., 2008. Effect of the shear intensity on fouling in submerged membrane bioreactor for wastewater treatment. J. Membr. Sci. 311, 173-181.

Guadie, A., Xia, S., Zhang, Z., Zeleke, J., Guo, W., Ngo, H.H., Hermanowicz, S.W., 2014. Effect of intermittent aeration cycle on nutrient removal and microbial community in a fluidized bed reactor-membrane bioreactor combo system. Bioresour. Technol. 156, 195-205.

Guo, X., Zhou, X., Chen, Q., Liu, J., 2013. Flow field and dissolved oxygen distributions in the outer channel of the Orbal oxidation ditch by monitor and CFD simulation. J. Environ. Sci. 25, 645-651.

Han, S.-S., Bae, T.-H., Jang, G.-G., Tak, T.-M., 2005. Influence of sludge retention time on membrane fouling and bioactivities in membrane bioreactor system. Process Biochem. 40, 2393-2400.

Jiang, T., Kennedy, M.D., Yoo, C., Nopens, I., van der Meer, W., Futselaar, H., Schippers, J.C., Vanrolleghem, P.A., 2007. Controlling submicron particle deposition in a sidestream membrane bioreactor: a theoretical hydrodynamic modelling approach incorporating energy consumption. J. Membr. Sci. 297, 141-151.

Judd, S., 2011. The MBR Book—Principles and Applications of Membrane Bioreactors for Water and Wastewater Treatment. Elsevier, UK.

Julien, S., Barbary, J.P., Lessard, P., 1999. A reduced order model for control of a single reactor activated sludge process. Math. Comput. Model. Dynam. Syst. 5, 337-350.

Khalili-Garakani, A., Mehrnia, M.R., Mostoufi, N., Sarrafzadeh, M.H., 2011. Analyze and control fouling in an airlift membrane bioreactor: CFD simulation and experimental studies. Process Biochem. 46, 1138-1145.

Krzeminski, P., Leverette, L., Malamis, S., Katsou, E., 2017. Membrane bioreactors - A review on recent developments in energy reduction, fouling control, novel configurations, LCA and market prospects. J. Membr. Sci. 527, 207-227.

Li, Y.L., Lin, P.J., Tung, K.L., 2011. CFD analysis of fluid flow through a spacer-filled disktype membrane module. Desalination 283, 140-147.

Littleton, H.X., Daigger, G.T., Strom, P.F., 2007. Application of computational fluid dynamics to closed-loop bioreactors: II. Simulation of biological phosphorus removal using computational fluid dynamics. Water Environ. Res. 79, 613-624.

Liu, X., Wang, Y., Waite, T.D., Leslie, G., 2015. Numerical simulation of bubble induced shear in membrane bioreactors: effects of mixed liquor rheology and membrane configuration. Water Res. 75, 131-145.

Liu, X., Wang, Y., Waite, T.D., Leslie, G., 2016. Numerical simulations of impact of membrane module design variables on aeration patterns in membrane bioreactors. J. Membr. Sci. 520, 201-213.

Lorain, O., Dufaye, P.-E., Bosq, W., Espenan, J.-M., 2010. A new membrane bioreactor generation for wastewater treatment application: strategy of membrane aeration management by sequencing aeration cycles. Desalination 250, 639-643.
Ndinisa, N.V., Fane, A.G., Wiley, D.E., Fletcher, D.F., 2006. Fouling control in a submerged flat sheet membrane system: Part II - Two-Phase flow characterization and CFD simulations. Sep. Sci. Technol. 41, 1411-1445.

Park, J.-S., Yeon, K.-M., Lee, C.-H., 2005. Hydrodynamics and microbial physiology affecting performance of a new MBR, membrane-coupled high-performance compact reactor. Desalination 172, 181-188.

Tang, B., Zhang, Z., 2014. Essence of disposing the excess sludge and optimizing the operation of wastewater treatment: rheological behavior and microbial ecosystem. Chemosphere 105, 1-13.

Wang, T., Zhang, Z., Ren, X., Qin, L., Zheng, D., Li, J., 2014a. Direct observation of singleand two-phase flows in spacer filled membrane modules. Sep. Purif. Technol. 125, 275-283.

Wang, X., Ding, J., Ren, N.-Q., Liu, B.-F., Guo, W.-Q., 2009. CFD simulation of an expanded granular sludge bed (EGSB) reactor for biohydrogen production. Int. J. Hydrogen Energy 34, 9686-9695.

Wang, X., Jia, X., Wen, J., 2011. Transient CFD modeling of toluene waste gas biodegradation in a gas-liquid-solid three-phase airlift loop reactor by immobilized Pseudomonas putida. Chem. Eng. J. 172, 735-745.

Wang, Z., Ma, J., Tang, C.Y., Kimura, K., Wang, Q., Han, X., 2014b. Membrane cleaning in membrane bioreactors: a review. J. Membr. Sci. 468, 276-307.

Wibisono, Y., Cornelissen, E.R., Kemperman, A.J.B., van der Meer, W.G.J., Nijmeijer, K., 2014. Two-phase flow in membrane processes: a technology with a future. J. Membr. Sci. 453, 566-602.

Wu, J., He, C., 2012. Effect of cyclic aeration on fouling in submerged membrane bioreactor for wastewater treatment. Water Res. 46, 3507-3515.

Yan, X., Wu, Q., Sun, J., Liang, P., Zhang, X., Xiao, K., Huang, X., 2016. Hydrodynamic optimization of membrane bioreactor by horizontal geometry modification using computational fluid dynamics. Bioresour. Technol. 200, 328-334.

Yan, X., Xiao, K., Liang, S., Lei, T., Liang, P., Xue, T., Yu, K., Guan, J., Huang, X., 2015. Hydraulic optimization of membrane bioreactor via baffle modification using computational fluid dynamics. Bioresour. Technol. 175, 633-637.

Yang, J., Vedantam, S., Spanjers, H., Nopens, I., van Lier, J.B., 2012. Analysis of mass transfer characteristics in a tubular membrane using CFD modeling. Water Res. 46, 4705-4712.

Yang, M., Wei, Y., Zheng, X., Wang, F., Yuan, X., Liu, J., Luo, N., Xu, R., Yu, D., Fan, Y., 2016a. CFD simulation and optimization of membrane scouring and nitrogen removal for an airlift external circulation membrane bioreactor. Bioresour. Technol. 219, 566-575.

Yang, M., Yu, D., Liu, M., Zheng, L., Zheng, X., Wei, Y., Wang, F., Fan, Y., 2016b. Optimization of MBR hydrodynamics for cake layer fouling control through CFD simulation and RSM design. Bioresour. Technol. 227, 102-111.

Yang, W., Cicek, N., Ilg, J., 2006. State-of-the-art of membrane bioreactors: Worldwide research and commercial applications in North America. J. Membr. Sci. 270, 201-211.

Yeo, A.P.S., Law, A.W.K., Fane, A.G., 2007. The relationship between performance of submerged hollow fibers and bubble-induced phenomena examined by particle image velocimetry. J. Membr. Sci. 304, 125-137.

Zhang, M., Lin, H., Shen, L., Liao, B.-Q., Wu, X., Li, R., 2017. Effect of calcium ions on fouling properties of alginate solution and its mechanisms. J. Membr. Sci. 525, 320-329.

Zhang, Q., Xu, R., Zheng, X., Fan, Y., 2013. Simulation and optimization of airlift external circulation membrane bioreactor using computational fluid dynamics. Water Sci. Technol. 69, 1846-1852.

Zhao, L., Zhang, M., He, Y., Chen, J., Hong, H., Liao, B.Q., Lin, H., 2016. A new method for modeling rough membrane surface and calculation of interfacial interactions. Bioresour. Technol. 200, 451-457. 